\title{
An example of innovative university teaching: the model of Constructive and Collaborative Professional Participation
}

\author{
Rosa Di Maso ${ }^{1}$, Maria Beatrice Ligorio ${ }^{2}$ \\ ${ }^{1}$ Department of Humanities, Social Science and Culture Industries, University of Parma, \\ Italy, ${ }^{2}$ Department of Education Science, Psychology, Communication, University of Bari, \\ Italy.
}

\begin{abstract}
This contribution presents a blended course model called Constructive and Collaborative Professional Participation (CCPP), developed since 2005. We will describe theories of reference, course structure, activities performed and methods adopted. Starting from a socio-constructivist framework, both online individual and group activities and offline individual and group activities were organized together with Role Taking, "expert" and "Jigsaw" groups inspired by the Aronson method, web-forum and in presence discussions aimed at building various products. The model has been implemented in university courses about Psychology of e-learning and involves companies from the field to professionalize the activities. Academic and business tutors have been purposely trained, to support students' participation. Following the Design Based Research methodology, at the end of each edition various kinds of data were collected: questionnaires, interviews, and focus groups with the students and feedback from the tutors and the companies involved. The course trained students on skills related to the syllabus, together with communication, organizational and self-assessment skills. Our results also showed how it was possible to develop identity positioning, in particular the transition from positions as students towards professional positioning.
\end{abstract}

Keywords: blended learning, innovative teaching, online participation 


\section{Introduction}

Today cultural scenario recognizes the centrality of educational systems and the need to innovate teaching practices as a crucial objective. From the Eighth Eurostudent Survey for the period 2016-2018 on Italian university students, emerges a judgment on the acquisition of problematic professional knowledge (Associazione Cimea, 2018). Even if four out of five students declare to be satisfied with their theoretical preparation, less than $50 \%$ think they have received a good professional preparation. This highlights the need for Higher Education to improve its role as trait d'union between the formative dimension and the professional domain. This implies a redefinition of its aims and modalities. Kelly and his collaborators (Kelly, Lesh \& Baek, 2014) affirm that it is necessary to develop in parallel the analysis of learning processes and those of teaching, looking for points of intersection between how we teach and how we learn. The tools and technologies used in the classroom are important, so the quality of the teachers is determined not only by their ability to teach but also by the capability to orchestrate a rich, stimulating and appropriate environment for students, by knowing how to choose the right tools and methods. This contribution presents a model built to respond to these indications.

\section{The model of Constructive and Collaborative Professional Participation (CCPP)}

The model called Constructive and Collaborative Professional Participation (CCPP), was developed on the basis of more than 10 years of consecutive application in a university course called "Educational and e-learning psychology", held at the University of Bari (Ligorio \& Annese, 2010; Ligorio \& Cucchiara, 2011; Ligorio \& Sansone, 2009). The model considers learning as a co-construction of knowledge and aims to encourage students to develop new ideas through the creation of both individual and group products (Cucchiara, Ligorio, \& Fujita, 2014). The theoretical framework inspiring the course is socio-constructivism (Berger \& Luckman, 1966; Gergen, 2001; Kelly, 1955; Potter, 1996; Shotter, 1993) and historical-cultural psychology (Cole, 1996; Scardamalia \& Bereiter, 2006). Another source of inspiration is the so-called Trialogical Learning Approach (TLA) (Paavola \& Hakkarainen, 2005). In TLA learning settings, students collaboratively develop new objects of inquiry, such as knowledge artefacts, practices, ideas, models and representations. These are 'boundary- objects' designed by one community (e.g., tertiary students) but intended for use in another (e.g., customers of e-learning entrepreneurs in our case).

Therefore, the CCPP model is guided by the idea that people build knowledge through the active production of meanings, products and forms of interaction, negotiation and social collaboration between different contexts. To this end, companies have been involved in the design and implementation of the model, so that the activities included into the model 
enhance the professionalization of the course. Online and offline activities are alternated and distributed across two modules (M1 and M2), with an average duration of four weeks for each module. M1 starts with a teacher lesson the in the classroom, during which the educational contents of the module are introduced. M1 ends with the definition of a research question, negotiated with the students, that guides all the activities of the module, which we will briefly describe later. M2 is characterized by the presence of companies that first present their core business and then propose to students to participate in the creation of corporate products. In this module, the learning methods already tested in the M1 will be re-proposed, with the appropriate adaptations. The model requires specially trained professional tutors, which act as mediators between teacher, students, and companies. The activities carried out by the students include:

- Independent individual activities (compilation and maintenance of an E-portfolio for the whole course; compilation of a self-assessment grid at the end of each module);

- Individual interdependent activities (in M1 a personal review of an assigned teaching material; in the M2 an individual report on the work performed with the company);

- Small group activities (collaborative creation of a conceptual map to answer to the research question in the M1; activities coordinated with the company chosen in the M2);

- $\quad$ Plenary activities (presentation of the work done in both modules).

To perform these activities, different types of collaborative learning techniques are used: (i) the Progressive Inquiry Model (PIM) (Hakkarainen \& Sintonen, 2002) which considers learning as a process of investigation starting from a broad and general question, proceeds towards its refinement, in order to stimulate the emergence of a critical and scientific thought. This model guides the discussion via web-forum; (ii) the Jigsaw method (Aronson, 1978) with which groups are initially created (called "expert groups”) to deepen a certain topic and later these groups are remixed and the participants - coming from different expert groups - are supposed to explain each other what they learn in the previous groups; (iii) Role Taking (Strijbos \& Weinberger, 2010) that allows one or more members of a group to take on explicitly defined functions, specific tasks and responsibilities. Students make turn in covering the roles so that each student can try out different ones. The CCPP model uses a type of assessment that encourages students to reflect on their own path and how they learn. During the course, self-evaluation and mutual evaluation (Topping, 2005) are supported through specific tools and interactive moments. The tools used are: (i) the eportfolio in which personal information is collected together with skills and abilities acquired or purse in the up-coming activities; (ii) the self-assessment form proposed to students at the end of each module, composed of different sections corresponding to the 
activities performed (reviews, collaborative products, covered roles, discussions); (iii) an evaluation grid drawn up jointly by the teacher and tutors.

\section{The changes made}

At the end of each edition of the course, systematic feedbacks were collected through specially prepared forms, from four different foci: (i) students self-assessment sheets; students interviews and Focus Group discussions; (ii) the academic tutors who provided feedback all along the course and questionnaires filled in at the end of the course; (iii) companies that have offered systematic feedback during the course, at the end but also in the time lag between editions; (iv) data recorded in the various platforms used (Forumcommunity, WhatsApp, corporate platforms).

The teacher collected and systematized the various feedbacks and, following the methodology of Designed Based Research (Clarke, Dede, Ketelhut, \& Nelson, 2006), identified ways of implementing the feedback in the subsequent edition. These are some of the most significant innovations introduced over the years:

a) We have moved from 10 modules to just two modules. Although a higher number of modules allowed for a greater exercise in the activities, this involved a considerable effort in terms of assessment because each module requires students' self-assessment and a joint teacher-tutor assessment. Furthermore, this generated too much anxiety in the students. In addition, companies increasingly required more time for the activities they proposed;

b) Greater presence of companies. In close interconnection with the previous point, it was decided to offer more time to interactions with companies. This was also a consequence of the adoption of the TLA as a theoretical framework, which lead toward a higher professionalization. In fact, the model was initially called Constructive and Collaborative Participation (CCP) and it was renamed as a result of the expansion of the presence of companies it was renamed Constructive and Collaborative Professional Participation (CCPP) to highlight the increase of companies presence;

c) The technological dimension was expanded. In the early editions, just one platform was used (Synergeia, no longer available); then we moved to more platforms used in combination with various technological tools such as Google Drive, DropBox, Padlet, Webinar, Yammer, LinkedIn, WhatsApp, Articulate, etc. Given the course content (e-learning), it seemed appropriate to offer an extensive technological experience. We also wanted to show, through the concrete use, the variability of objectives that can be pursued with each digital tool. Moreover, we wanted to diversify and expand the range of technology in order to guarantee more ubiquitous and personalized training. 
d) More transversal skills. From a follow-up study (Ligorio, Di Maso, \& McLay, 2019 in preparation) we found that students remember and appreciate more skills of this kind (communication, group work, self-assessment) as they are better transferable to others contexts, either educational and professional. Therefore, we have amplified the occasions for cooperative work, exchange of mutual feedback, Role Taking, and self-assessment.

e) Simplification of the assessment. Introducing teaching innovation also implies adopting appropriate assessment models. In particular, it was decided not to assess informal communication to protect students free expression. At the same time, it was defined a protocol able to balance the assessment of individual contributions with the evaluation of the processes and products of the group (Sansone \& Ligorio, 2015). In the management of this protocol, tutors, companies and students themselves are actively involved.

\section{Some results}

The effectiveness of the CCPP model has been demonstrated from different points of view.

For example, the Role Taking, and in particular the role of peer-tutor (Sansone, Ligorio, \& Buglass, 2016), allows to support and structure online participation through various types of interaction styles, such as the supportive style that stimulates participation and the motivation to collaborate. We found that, through Role Taking, students learnt to consider the group as a means of learning. The model also favors the management and promotion of online agency (Ligorio, Impedovo, \& Arcidiacono, 2017) in particular the set of proposed activities and the collaboration within groups aimed at producing challenging products, are elements able to empower agency. Finally, particularly interesting are the changes tracked down about students positioning. We found an emerging sense of group, therefore an increasing We-positioning (Loperfido, Sansone, Ligorio, \& Fujita, 2014), and a transition from a positioning as student towards professional positioning (Amenduni \& Ligorio, 2017). We believe this data can be at least partially considered as the reason why about $10 \%$ of students who attended the course finds a job in the field of e-learning.

Although this paper is mostly based on results already published, its originality lies on giving a comprehensive vision of the course and a systematic synthesis of the main results gathered so far. We also reported here for the first time the list of all the changes occurred in ten years of applications of the model. The application of the Designed-Based Research (Clarke, et al., 2006) allowed to improve the model from one edition to the subsequent and to intercept needs and changes dictated by the specific context of each edition. For example, students showed an increase from one edition to another in their positive attitude towards the use of technologies. The companies, from their side, have revealed an increasing interest in the course by proposing better defined activities and requiring more 
time. The tutors have also refined their monitoring and support management skills, contributing to increasing the course effectiveness.

Finally, we consider this model as capable to innovate education by proposing a professionalization of teaching and learning based on contacts with real stakeholders, by collaboratively building challenging products and by fostering the so-called soft skills.

\section{References}

Amenduni, F. \& Ligorio, M.B. (2017). Becoming at the borders: the role of positioning in boundary-crossing between university and workplaces. Cultural-Historical Psychology. Vol. 13, no. 1, pp. 89-104.

Aronson, E. (1978). The jigsaw classroom. Oxford, England: Sage

Associazione Cimea (2018). Ottava indagine Eurostudent. Le condizioni di vita degli studenti universitari 2016-2018 [Eighth Eurostudent survey. The living conditions of university students 2016-2018]. Roma. Retrived from http://www.eurostudent.it/PDF/ottava-indagine-2016\%E2\%80\%932018/mobile/\#p=1

Berger, P. \& Luckman, T. (1966). The social Construction of Reality: A Treatise it's the Sociology of Knowledge. New York: Anchor Books, 1966.

Clarke, J., Dede, C., Ketelhut, D. J., \& Nelson B. (2006). A Design-Based Research Strategy to promote scalability for educational innovations, Educational Technology, 46 (3), pp. 27-36.

Cole, M. (1996). Cultural Psychology: A once and future discipline. Cambridge: Harvard University Press.

Cucchiara, S., Ligorio, M. B., \& Fujita, N. (2014). Understanding Online Discourse Strategies for Knowledge Building Through Social Network Analysis. In H. Lim, \& F. Sudweeks (Eds.), Innovative Methods and Technologies for Electronic Discourse Analysis (pp. 42-62). Hershey, PA: Information Science Reference.

Gergen, K.J. (2001). Psychological science in a postmodern context. American Psychologist, 56, p. 803-813.

Hakkarainen, K. \& Sintonen, M. (2002). Interrogative Model of Inquiry and ComputerSupported Collaborative Learning. Science \& Education, 11, p. 25-43.

Kelly, G.A. (1955). The Psychology of Personal Constructs. New York: Norton.

Kelly, A., Lesh, R., \& Baek, J. (Eds.). (2014). Handbook of design research methods in education. New York: Routledge.

Ligorio, M. B., Sansone, N. (2009). Structure of a Blended University course: Applying Constructivist principles to a blended course. In C. R. Payne (Ed.) Information Technology and Constructivism in Higher Education: Progressive Learning Frameworks. London, IGI Global, pp. 216-230

Ligorio, M. B., \& Annese, S. (2010) Blended activity design approach: a method to innovate e-learning for higher education. In A. Blachnio, Przepiorka, A., Rowiński T. (Eds.) Psychology Research, pp. 165-188 Warsaw: CSWU Press. 
Ligorio, M. B., \& Cucchiara, S. (2011). Blended Collaborative Constructive Participation (BCCP): A model for teaching in higher education. eLearningPapers, 27th issue (http://www.elearningeuropa.info/it/node/111469).

Ligorio, M.B., Impedovo, M. A., \& Arcidiacono, F. (2017). Agency online: Trends in a university learning course. Technology, Pedagogy and Education. Vol. 26, no. 5, 529543.

Ligorio, M.B., Di Maso, R., \& McLay, K. (2019). Assessing an innovative model for university teaching. Manuscript in preparation.

Loperfido, F.F., Sansone N., Ligorio, M.B., \& Fujita, N. (2014). Understanding I/We positions in a blended university course: Polyphony and chronotopes as dialogical features. QWERTY, vol. 9, p. 51-66.

Paavola, S., \& Hakkarainen, K. (2005). The knowledge creation metaphor-An emergent epistemological approach to learning. Science \& Education, 14(6), 535-557.

Potter, J. (1996). Representing Reality. Discourse, Rhetoric and Social Construction. In J.E. Richardson (Ed.), Handbook of qualitative research methods for psychology and social sciences pp. 136-178. Leicester: British Psychological Society.

Sansone, N., \& Ligorio, M. B. (2015). A protocol for multidimensional assessment in university online courses. Research on Education and Media. Vol. 7, 1

Sansone, N., Ligorio, M. B., \& Buglass, S. (2016). Peer e-tutoring: Effects on students' participation and interaction style in online course. Innovations in Education and Teaching International. Vol 55, 1, pp. 13-22.

Scardamalia, M. \& Bereiter, C. (2006). Knowledge building: Theory pedagogy, and technology. In K. Sawyer (Ed.), Cambridge Handbook of the learning Sciences, pp. 97118. New York: Macmillan Reference, USA.

Shotter, J. (1993). Cultural Politics of Everyday Life: Social Constructionism, Rhetoric, and Knowing of the third Kind. Milton Keyne: Open University Press.

Strijbos, J.W., \& Weinberger, A. (2010). Emerging and scripted roles in computersupported collaborative learning. Computers. Human Behavior, 26, pp. 491-494.

Topping K.(2005). Trends in Peer Learning. Educational Psychology, 25(6), pp.631-45. 